\title{
Tramadol versus placebo for labor analgesia in low risk women: a randomized controlled trial
}

\author{
Aastha Raheja, Krishna Agarwal*, Rini Pachori, Gauri Gandhi
}

Department of Obstetrics and Gynecology, Maulana Azad Medical College, New Delhi, India

Received: 12 November 2019

Accepted: 05 December 2019

\section{*Correspondence:}

Dr. Krishna Agarwal,

E-mail: drkrishna.agarwal@gmail.com

Copyright: () the author(s), publisher and licensee Medip Academy. This is an open-access article distributed under the terms of the Creative Commons Attribution Non-Commercial License, which permits unrestricted non-commercial use, distribution, and reproduction in any medium, provided the original work is properly cited.

\section{ABSTRACT}

Background: In low- and middle-income countries epidural analgesia is generally not available and practically no form of labor analgesia is given to the majority of the parturient. The purpose of study was to evaluate the safety and efficacy of tramadol as a labor analgesic during first stage of labor.

Methods: Pregnant women admitted in the labor room satisfying the eligibility criteria were randomized to receive intramuscular injection of either $100 \mathrm{mg}$ tramadol or $2 \mathrm{ml}$ distilled water. Visual analogue score (VAS) was assessed at the beginning and every hour till 4 hours. Pain satisfaction, duration of second stage of labor, fetal heart rate, mode of delivery, and any maternal side effects of the study drug were recorded. Neonatal evaluation using Apgar score at 1 and 5 minutes was done. For statistical analysis Student t-test, Chi Square test and Fisher's exact test were used.

Results: Total of 86 women were included in the study. The VAS scores were significantly lower in the tramadol group at 1, 2 and 3 hours after the administration. Pain relief satisfaction was significantly higher in the tramadol group. Rate of cervical dilatation, duration of the second and the third stage, need for instrumental delivery or lower segment caesarean section, rate of fetal distress and Apgar score at one and five minutes were comparable in both the groups. Nausea was significantly higher in tramadol group.

Conclusions: Tramadol is a safe and efficacious drug which is inexpensive, easily available and easy to administer with few minor side effects. It can be used as a labour analgesic as an alternative to epidural analgesia in settings where epidural analgesia is not available. Trial registration: Clinicaltrials.gov PRS registration number: NCT02999594.

Keywords: Labor analgesia, Pain relief, Tramadol, Visual analogue score

\section{INTRODUCTION}

Labour pain is considered as one of the most severe form of pain. Provision of epidural analgesia has become increasingly common in high income countries (HIC) for relieving labour pain. However, the same is not available in low- and middle-income countries (LMIC) like India due to limited availability of anaesthetists. Consequently, the overwhelming majority of deliveries in India take place without any analgesia at all. ${ }^{1}$ An effective alternative for these patients may be the use of parenteral opioids, which have the advantage of ease of administration, low cost, easy availability and no requirement of an anaesthetist for its administration. ${ }^{2}$ Although opioids such as pethidine are associated with reduced labour pain, these medications increase maternal drowsiness, nausea and vomiting and may cause respiratory depression in the newborn. ${ }^{3}$

Tramadol, a synthetic analogue of codeine and a weak opioid agonist, has been found to have analgesic efficacy similar to that of pethidine but with less sedative effect on 
the mother and less neonatal respiratory depression. ${ }^{4,5}$ In addition, a decrease in duration of labour with the use of tramadol has been reported in literature..$^{2,4}$

However, its use for alleviating labour pain has not been studied well. The systematic review of literature revealed a systematic review (2010) from Cochrane collaboration, which addressed the issue of analgesia during labour and included a total of 54 studies comparing one opioid with placebo or another opioid. ${ }^{6}$ A variety of analgesic agents were used. Only one of 54 included studies compared the analgesic effect of tramadol with no treatment group and found that only 5 women in treatment group reported analgesia to be satisfactory which came out to be statistically insignificant.

Following the aforementioned Cochrane review, there were two additional research articles that compared tramadol versus placebo for labor analgesia. ${ }^{7,8}$ However neither of the two studies practice proper randomization and blinding.

Thus, there is paucity of evidence on this issue and therefore this study. In our study we aimed to study the analgesic efficacy and safety of intramuscular tramadol for labour analgesia.

\section{METHODS}

It was a randomized controlled trial conducted in a tertiary care hospital setting, conducted from November 2016 to April 2018.

The pregnant women admitted in the labor room were assessed for eligibility. The inclusion criteria were: women delivering for the first time (nulliparous); well established labor (having three or more contractions in span of 10 minutes); cervical dilatation $4 \mathrm{~cm}$ or more; and more than or equal to $80 \%$ effacement of cervix. The exclusion criteria were any medical disorders (known diabetes mellitus, hypertensive disorder etc.) and any obstetric high-risk factor (antepartum bleeding, malpresentation, fetal distress, infection etc.).

Primary outcome would be to observe the improvement in visual analogue scale (VAS)score and patient satisfaction. Secondary outcome measures would include duration of labour and presence of any maternal or foetal adverse events during study.

Computer assisted random sequence number in block size of 4, 6 and 8 was generated by a person who was not involved in the study. The opaque envelops of drug and placebo were prepared and numbered according to the random number by the primary investigator.

All the participants were fully informed about the study objectives and procedures. After taking written informed consent, the participants were assigned the enrolment number. According to the enrolment number, the envelope was opened by a staff nurse not involved in the care of the participants and the same staff nurse administered the drug. The used empty vials were kept in the same envelop, sealed in a blinded manner and kept for future reference. The intervention was not repeated.

The investigator who filled the VAS sheet was blinded for the type of intervention. Visual analogue score on the visual analogue scale (VAS) was assessed at the beginning (before the intervention) and every hour till 4 hours.

Pulse and blood pressure of the participants were recorded before administration and every 30 minutes after giving the drug. Progress of the labor was assessed and if required, oxytocin infusion was administered.

Duration of first and second stage of labor, fetal heart rate, mode of delivery, and any intrapartum complications as well as any maternal side effects of the study drug (nausea, vomiting, and dizziness) were recorded.

Following delivery, neonatal evaluation using Apgar score at 1 and 5 minutes was done by the pediatrician, and any complications were noted.

Data was collected on a predesigned proforma and was entered in the excel sheet.

For an alpha error of 5 and $80 \%$ power of study, considering the reduction in severity of pain on visual analogue scale by 2 points (absolute reduction of 20\%) with the use of IM tramadol, the sample size was calculated to be 43 in both the arms.

Data was analysed using Stata statistical software version 11. Mean \pm SD and proportions were calculated. As the values of mean and SD were normally distributed, two sample t-test was used to compare the means.

\section{Statistical analysis}

Pearson's Chi square test was used to compare the proportions and Fisher's exact test was used where the value of any parameter was 5 or less. The P-value of < 0.05 was considered significant.

\section{RESULTS}

A total of 86 women were included in the study. The demographic and clinical profile of the participants in the tramadol group and the placebo group were comparable (Table 1).

Table 2 shows VAS score at $0,1,2,3$ and 4 hours in the two groups. The mean VAS score at the time of administration of drug in both the groups was around 8 and dilatation of cervix was $5-6 \mathrm{~cm}$. 
Table 1: Clinico-demographic profile of the participants.

\begin{tabular}{|c|c|c|c|}
\hline & $\begin{array}{l}\text { Study } \\
\text { group } \\
(n=\mathbf{4 3})\end{array}$ & $\begin{array}{l}\text { Control } \\
\text { group } \\
(n=43)\end{array}$ & $\begin{array}{l}\text { P- } \\
\text { value }\end{array}$ \\
\hline $\begin{array}{l}\text { Age (mean } \pm \\
\text { SD, year) }\end{array}$ & $23.88 \pm 3.08$ & $23.95 \pm 3.32$ & 0.9199 \\
\hline \multicolumn{4}{|l|}{ Literacy } \\
\hline Illiterate & 5 & 2 & \\
\hline $\begin{array}{l}\text { Primary } \\
\text { school }\end{array}$ & 24 & 23 & \\
\hline $\begin{array}{l}\text { Secondary } \\
\text { school }\end{array}$ & 11 & 14 & \\
\hline $\begin{array}{l}\text { Higher } \\
\text { secondary }\end{array}$ & 2 & 3 & \\
\hline Graduate & 1 & 1 & \\
\hline \multicolumn{4}{|l|}{ Occupation } \\
\hline Housewife & 43 & 40 & \multirow{2}{*}{0.078} \\
\hline Others & 0 & 3 & \\
\hline \multicolumn{4}{|c|}{ Income (INR per mo.) } \\
\hline 20000 & 5 & 4 & \multirow{4}{*}{0.570} \\
\hline $20000-40000$ & 37 & 36 & \\
\hline $40000-60000$ & 1 & 3 & \\
\hline \multicolumn{3}{|l|}{$>60000$} & \\
\hline \multicolumn{4}{|l|}{ Parity } \\
\hline primigravida & 26 & 23 & \multirow[b]{2}{*}{0.514} \\
\hline $\begin{array}{l}\text { Previous } \geq 1 \\
\text { abortion }\end{array}$ & 17 & 20 & \\
\hline \multicolumn{4}{|c|}{ Period of gestation } \\
\hline $\begin{array}{l}\text { (weeks, } \\
\text { mean } \pm \text { SD) }\end{array}$ & $38.79 \pm 1.38$ & $38.76 \pm 1.32$ & \\
\hline \multicolumn{4}{|l|}{ BMI } \\
\hline $\begin{array}{l}\left(\mathrm{Kg} / \mathrm{mt}^{2}\right. \\
\text { mean } \pm \mathrm{SD})\end{array}$ & $26.06 \pm 2.507$ & $26.06 \pm 2.969$ & 0.987 \\
\hline \multicolumn{4}{|l|}{ Systolic BP } \\
\hline $\begin{array}{l}(\mathrm{mm} \mathrm{Hg} ; \\
\text { mean } \pm \mathrm{SD})\end{array}$ & $116.83 \pm 6.50$ & $116.74 \pm 6.04$ & 0.945 \\
\hline \multicolumn{4}{|l|}{ Diastolic BP } \\
\hline $\begin{array}{l}(\mathrm{mm} \mathrm{Hg} \\
\text { mean } \pm \mathrm{SD})\end{array}$ & $75.90 \pm 6.12$ & $76.41 \pm 6.83$ & \\
\hline \multicolumn{4}{|l|}{ Pallor } \\
\hline Absent & 29 & 36 & \multirow{3}{*}{0.145} \\
\hline Mild & 9 & 3 & \\
\hline Moderate & 5 & 4 & \\
\hline \multicolumn{4}{|l|}{ Hemoglobin } \\
\hline Mean \pm SD & $10.83 \pm 1.07$ & $11.10 \pm 1.03$ & 0.232 \\
\hline
\end{tabular}

Data expressed as Mean \pm SD and percentage (\%).

The scores were lower in the tramadol group at 1,2 and 3 hours of administration as compared to the placebo group and the difference was found to be statistically significant. However, the VAS score at the end of 4 hours in the tramadol group again increased and the difference in the VAS score between the two groups was insignificant at this time.
Table 2: VAS score at $0,1,2,3$ and 4 hours after giving the tramadol and placebo.

\begin{tabular}{|llll|}
\hline VAS & $\begin{array}{l}\text { Study group } \\
(\mathbf{n}=\mathbf{4 3})\end{array}$ & $\begin{array}{l}\text { Control group } \\
(\mathbf{n}=\mathbf{4 3})\end{array}$ & P-value \\
\hline 0 & $8.39 \pm 0.659$ & $8.27 \pm 0.590$ & 0.391 \\
\hline 1 & $7.25 \pm 0.875$ & $8.55 \pm 0.733$ & 0.00 \\
\hline 2 & $7.47 \pm 1.45$ & $8.86 \pm 0.742$ & 0.00 \\
\hline 3 & $8.65 \pm 0.937$ & $9.28 \pm 0.458$ & 0.0007 \\
\hline 4 & $9.09 \pm 0.830$ & $9.38 \pm 0.501$ & 0.199 \\
\hline
\end{tabular}

Data expressed as Mean \pm SD.

Table 3: Secondary outcomes.

\begin{tabular}{|c|c|c|c|}
\hline & $\begin{array}{l}\text { Study } \\
\text { group } \\
(\mathbf{n}=\mathbf{4 3})\end{array}$ & $\begin{array}{l}\text { Control } \\
\text { group } \\
(n=43)\end{array}$ & $\begin{array}{l}\text { P- } \\
\text { value }\end{array}$ \\
\hline Nausea & $6(13.9 \%)$ & $0(0 \%)$ & 0.011 \\
\hline Vomiting & $0(100 \%)$ & $0(100 \%)$ & \\
\hline Sleepiness & $2(4.65 \%)$ & $3(6.97 \%)$ & 0.645 \\
\hline $\begin{array}{l}\text { Rate of cervical } \\
\text { dilatation }(\mathrm{cm} / \\
\text { hour) }\end{array}$ & $1.58 \pm 0.487$ & $1.58 \pm 0.378$ & 0.963 \\
\hline $\begin{array}{l}\text { Duration of } 2^{\text {nd }} \\
\text { stage (minutes) }\end{array}$ & $44.52 \pm 23.8$ & $41.45 \pm 19.3$ & 0.519 \\
\hline $\begin{array}{l}\text { Duration of } 3^{\text {rd }} \\
\text { stage (minutes) }\end{array}$ & $5.34 \pm 2.42$ & $5.83 \pm 2.36$ & 0.354 \\
\hline $\begin{array}{l}\text { Instrumental } \\
\text { delivery }\end{array}$ & $3(6.97 \%)$ & $3(6.97 \%)$ & 1.00 \\
\hline LSCS & $3(6.97 \%)$ & $3(6.97 \%)$ & 1.00 \\
\hline Fetal distress & $5(11.6 \%)$ & $6(13.9 \%)$ & 0.747 \\
\hline Apgar 1 & $8.97 \pm 0.152$ & $8.86 \pm 0.515$ & 0.159 \\
\hline Apgar 5 & $9 \pm 0$ & $9 \pm 0$ & 1.00 \\
\hline \multicolumn{4}{|l|}{ Mild PPH } \\
\hline Atonic & $3(6.97 \%)$ & $0(0 \%)$ & \multirow{2}{*}{0.041} \\
\hline Cervical tear & $1(2.32 \%)$ & $0(0 \%)$ & \\
\hline Severe & 0 & 0 & \\
\hline NICU & $0(0 \%)$ & $1(2.32 \%)$ & 0.314 \\
\hline
\end{tabular}

Data expressed as Mean \pm SD and percentage (\%).

Nausea was significantly high in the tramadol group (Table 3). However, none of the women in the either group had vomiting. Rate of cervical dilatation, duration of the second and the third stage were comparable between the two groups. Rate of foetal distress and need for instrumental delivery or LSCS were comparable in both the groups. There was no statistical difference in the Apgar score at one and five minutes. Only 1 baby in control group was admitted in NICU.

Mild postpartum haemorrhage was observed in 4 cases $(9.30 \%)$ of study group however no PPH was observed in the control group (Table 3 and 4). Two of the cases had retained bits of membranes and one case had tear in the lateral vaginal wall as the cause for PPH. Only one case had atonic PPH which was controlled with uterine massage and uterotonics. Therefore, it seems unlikely that tramadol predisposes for postpartum haemorrhage. 
Table 5 shows the perception about pain relief among the subjects. $50 \%$ of the participants in the study group were moderately satisfied with the pain relief while $30 \%$ said it was okay in relieving pain. Majority of the participants in the control group were not satisfied with the pain relief.
The difference in pain satisfaction in both the groups was statistically significant. About half of the participants in study group had liked to have a repeat dose and recommend the same drug in next pregnancy.

Table 4: Details of subjects who had PPH.

\begin{tabular}{|c|c|c|c|c|c|c|}
\hline $\begin{array}{l}\text { Sr. } \\
\text { No. }\end{array}$ & Gravidity & $\begin{array}{l}\text { Period of gestation } \\
\text { (weeks) }\end{array}$ & Haemoglobin & $\begin{array}{l}\text { Mode of } \\
\text { delivery }\end{array}$ & Cause of PPH & $\begin{array}{l}\text { Amount of } \\
\text { blood loss }\end{array}$ \\
\hline 1 & Primigravida & $40+5$ & 9.8 & $\begin{array}{l}\text { Low forceps } \\
\text { for FD }\end{array}$ & $\begin{array}{l}\text { Bits of membranes } \\
\text { removed }\end{array}$ & 600 \\
\hline 2 & Primigravida & $40+5$ & 14 & Vaginal & Mild atonic & 700 \\
\hline 3 & Primigravida & 36 & 10.4 & Vaginal & $\begin{array}{l}\text { Tear in lateral vaginal } \\
\text { wall }\end{array}$ & 650 \\
\hline 4 & G2A1 & 39 & 10.4 & Vaginal & $\begin{array}{l}\text { Bits of membranes } \\
\text { removed }\end{array}$ & 500 \\
\hline
\end{tabular}

Table 5: Perception about pain relief among the subjects.

\begin{tabular}{|c|c|c|c|}
\hline & $\begin{array}{l}\text { Study } \\
\text { group } \\
(n=43)\end{array}$ & $\begin{array}{l}\text { Control } \\
\text { group } \\
(n=43)\end{array}$ & $\begin{array}{l}\text { P- } \\
\text { value }\end{array}$ \\
\hline \multicolumn{4}{|l|}{ Pain relief satisfaction } \\
\hline \multicolumn{3}{|l|}{ Highly satisfied } & \multirow{5}{*}{0.00} \\
\hline Moderately satisfied & 5 & 2 & \\
\hline It is okay & 22 & 0 & \\
\hline Not satisfied & 14 & 12 & \\
\hline Highly unsatisfied & 2 & 29 & \\
\hline $\begin{array}{l}\text { Would like to have } \\
\text { repeat dose }\end{array}$ & 22 & 2 & 0.00 \\
\hline $\begin{array}{l}\text { Recommend same drug } \\
\text { in next pregnancy }\end{array}$ & 22 & 2 & 0.00 \\
\hline
\end{tabular}

\section{DISCUSSION}

\section{Primary outcomes}

Our study reiterates the fact that in active phase of labour, the labour pain is of high intensity (pain VAS score of more than 8), and this intensity gradually increases as the labour advances (Table 2). The mean VAS score for labour pain, just before administration of drug (zero hour), was $8.39 \pm 0.66$ in the tramadol group and $8.27 \pm 0.59$ in the placebo group. Most of the participants received injection at 5-6 centimeters cervical dilatation. The pain VAS score in the tramadol group was significantly lower than the placebo group at the end of first, second and the third hour. The pain score at the end of fourth hour was only insignificantly lower in the tramadol group as compared to the placebo group.

The pain VAS score in the tramadol group started rising after first hour. It can be explained by the fact that as the labour advanced the intensity of pain increased which is also seen by the trend in VAS score of placebo group. Concurrently, the effect of tramadol also started to wear off after the first hour thus contributing to increase in the pain VAS score in the tramadol group.

At zero hour the pain VAS score was insignificantly lower in the placebo group as compared to tramadol group, the score was significantly higher in the placebo group at the end of the first, the $2^{\text {nd }}$ and the $3^{\text {rd }}$ hour. The score was also higher at the end of 4th hour in the placebo group as compared to the tramadol group, however the difference was not significant.

Few studies have looked at the efficacy of tramadol for labor analgesia. ${ }^{9-12}$

Hema et al, studied intravenous paracetamol versus intramuscular tramadol as intrapartum labour analgesic. It was demonstrated that $100 \mathrm{mg}$ intramuscular tramadol had onset within 10min and the action lasted for 2-3 hours. ${ }^{9}$

In another study by Chandneni $\mathrm{K}$ et al, $100 \mathrm{mg}$ tramadol and $30 \mathrm{mg}$ pentazocine was given in 30 parturients in active labour. Repeat dose of $50 \mathrm{mg}$ tramadol or $15 \mathrm{mg}$ pentazocine was injected intramuscular after 4 hours if woman was still in first stage. In Tramadol group pain relief was observed in $80 \%$ cases, effect started as early as 7-8 min and continued for 2.13 hours. While in Pentazocine group pain relief was observed in only $60 \%$ cases with delayed onset (15-16 $\mathrm{min})$, effect lasted for 2.67 hours. $^{10}$

The duration of tramadol analgesia lasted for 4 hours in a study by Patil et al, however a repeat dose of $50 \mathrm{mg}$ tramadol was given after $100 \mathrm{mg}$ dose in those who did not respond well to the initial dose after 1 hour. The average onset of pain relief was $15 \mathrm{~min}$. Good pain relief 
was noted in $58 \%$ of the parturients, moderate relief in $30 \%$ and mild relief in $12 \%$. This study emphasised that duration of analgesia can be prolonged by repeating the dose of the drug. However, in our study we did not repeat the dose. ${ }^{11}$

Rani et al, in a similar study from Hyderabad on 100 pregnant women assessed the safety and efficacy of intramuscular tramadol as an analgesic in labor and compared it with placebo group, however it was not a randomized study. Good pain relief was observed in $56 \%$ and moderate pain relief was in $44 \%$ of the primigravidas at 15 minutes post injection in the tramadol group. ${ }^{8}$

Kale et al, in a similar study but without blinding, reported that $55 \%$ of participants had more than $50 \%$ relief after 1 hour of $100 \mathrm{mg}$ tramadol injection whereas only $17.5 \%$ of participants had more than $50 \%$ pain relief in the placebo group. While $77.5 \%$ of cases in tramadol group had significant pain relief after 2 hours as compared to only $27.5 \%$ in the placebo group. ${ }^{7}$

Kushtagi et al, compared $50 \mathrm{mg}$ tramadol, $100 \mathrm{mg}$ tramadol and $75 \mathrm{mg}$ meperidine. It was reported that proportion of cases with satisfactory to good pain relief (VAS difference $>5$ ) after 2 hours of administration was $35.2 \%, 61.8 \%$ and $70.3 \%$ in tramadol $50 \mathrm{mg}$, tramadol $100 \mathrm{mg}$ and meperidine $75 \mathrm{mg}$ respectively. Side effects such as nausea, vomiting, drowsiness and fatigue was significantly high in meperidine group. The effect seems to be quite significant as compared to our study (VAS score difference $>5$ ), however in this study there was no randomization, blinding or placebo control. ${ }^{12}$

Makkar et al, in a prospective, randomized, double blind study from Northern India evaluated the efficacy and safety of paracetamol in comparison to tramadol for pain relief during active labor. Lower mean VAS scores were reported in both the groups till 120 minutes. ${ }^{14}$

Almost all the studies have suggested that tramadol is effective in reducing intensity of labour pain as has been seen in our study.

\section{Secondary outcomes}

In our study nausea was significantly higher in the tramadol group as compared to the placebo group. However, none of the women in the either group had vomiting. There was no statistical difference in the APGAR score at one and five minutes. Only 1 baby in control group was admitted in NICU. Need for instrumental delivery or LSCS and incidence of foetal distress were comparable in both the groups

Similar findings were reported in other studies. ${ }^{8,11,14}$ Patil et al, reported that majority of the parturients who received tramadol did not suffer from any adverse effect and only $16 \%$ had minor adverse effects. Apgar score in the new born was $>7$ in $96 \%$ at $1 \mathrm{~min}$ and in $100 \%$ at 5 min. ${ }^{11}$ Lallar et al, reported minor side effects like nausea and vomiting in very few patients. ${ }^{14}$

Rani et al found that majority of them did not suffer any side effects and only $7 \%$ has complained of restlessness, dizziness, headache and $3.5 \%$ had nausea and vomiting. ${ }^{8}$

Mild postpartum haemorrhage was observed in 4 cases $(9.30 \%)$ of the tramadol group however no PPH was observed in the placebo group. In two of the cases, the cause was retained bits of membranes and in one case it was traumatic PPH. Only one case had mild atonic PPH which was controlled with uterine massage and uterotonics, which could be just a chance factor, therefore, it seems unlikely that tramadol predisposes to postpartum haemorrhage. There was no case of severe PPH. None of the other studies have reported increase in incidence of $\mathrm{PPH}^{7-12}$ Rate of cervical dilatation, and duration of the second and the third stage of labour were comparable in both the groups in our study. The study by Rani et al reported that the overall duration of labour was decreased in tramadol group (4.13 hours) when compared to placebo group (6.24 hours). ${ }^{8}$

Kale et al, found that average duration of $1^{\text {st }}$ stage of labour was slightly less in tramadol group and $2^{\text {nd }}$ stage was slightly less in control group but difference was not statistically significant. ${ }^{7}$ In our study the difference in duration of second and third stage of labor between the two groups was insignificant. Therefore, tramadol does not have any effect on the progression of labour.

In our study $50 \%$ of the participants in the study group were moderately satisfied with the pain relief while $30 \%$ said that pain relief was just okay. The difference the satisfaction in pain relief between the two groups was statistically significant. About half of the participants in tramadol group said that they would like to have a repeat dose and recommended the same drug in next pregnancy. None of the other studies have reported about patient satisfaction in pain relief..$^{7-12}$

The strength of our study is that it was a blinded placebo controlled randomized trial with adequate power. Blinding was done at every step including the generation of random number, the drug administration, data collection, data entry and data analysis.

The limitation of our study is that we did not plan for the repeat dose, which could have provided valuable insight about the maintenance of the analgesic effect.

\section{CONCLUSION}

Tramadol reduces severity of labour pain, reduction in VAS score was 1.14 at the end of first hour and it was 0.92 at the end of second hour. So, it may be inferred that as the weight in pregnancy is more, dose required to bring about relief of more than 2 on VAS scale may be higher, which may be further studied. Though almost 
$50 \%$ women had moderate pain relief and they demanded the same drug to be given during labour in next pregnancy.

Tramadol is able to sustain relief in pain of the labour up to 2-3 hours of administration and therefore a repeat dose would be required for maintenance of pain relief. So further study could be planned to look at the optimum timing of repeat dose of tramadol.

It is safe to use with few minor side effects like nausea. It has no sedative effect on mother or respiratory depression in the neonate. It does not increase the rate of instrumental delivery or LSCS. Tramadol does not prolong the duration of labour.

Therefore, tramadol is a safe, efficacious, cheap, easy to administer, easily available drug with very few minor side effects and can be used as a labour analgesic in LMICs as an alternative to epidural analgesia.

Funding: No funding sources

Conflict of interest: None declared

Ethical approval: The study was approved by the Institutional Ethics Committee

\section{REFERENCES}

1. Elbohoty AE, Abd-Elrazek H, Abd-El-Gawad M, Salama F, El-Shorbagy M, Abd-El-Maeboud KH. Intravenous infusion of paracetamol versus intravenous pethidine as an intrapartum analgesic in the first stage of labor. Int $\mathbf{J}$ Gynaecol Obstet. 2012;118:7-10.

2. Khooshideh M. A comparison of tramadol and pethidine analgesia on the duration of labour: A randomised clinical trial. Aust $\mathrm{N}$ Z J Obstet Gynaecol. 2009;49:59-63.

3. Simkin P, Dickersin K. Control of pain in labor. In: Enkin M, Keire MJNC, Renfrew M, Neilson JA, editors. A guide to effective care in pregnancy and childbirth: United Kingdom: Oxford University Press; 1996:247-61.

4. Pandya ST. Labour analgesia: recent advances. Indian J Anaesth. 2010;54:400.
5. Viegas O, Khaw B, Ratnam S. Tramadol in labour pain in primiparous patients. A prospective comparative clinical trial. Eur J Obstet Gynecol Reprod Biol. 1993;49:131-5.

6. Ullman R, Smith LA, Burns E, Mori R, Dowswell T. Parenteral opioids for maternal pain management in labour. Cochrane Library. 2010:9.

7. Kale T, Kamble S. A prospective study of effect of intramuscular tramadol in labor analgesia. Int J App Basic Med Res. 2015;5:87-91.

8. Rani MS, Prasad KV. Comparative study of efficacy of tramadol as an analgesic in labor on primigravida and mutligravida. Int $\mathbf{J}$ Pharma Res Rev. 2015;3:2347-50.

9. Hema M, Ramappa R, Sandesh M, Akash B. Intravenous paracetamol infusion versus intramuscular tramadol as an intrapartum labor analgesic. Int J Reprod Contracept Obstet Gynecol. 2015;4:1726-9.

10. Chandnani K. Sainee HB. Pain relief in labour: tramadol versus pentazocine. Int $\mathbf{J}$ Reprod Contracept Obstet Gynecol. 2013;2:186-18.

11. Patil S, Somashekara SC, Veerabhadra GK, Bhanurekha G, Jayanthi R, Deepalaxmi S. Tramadol analgesia in labor. Int $\mathbf{J}$ Pharm Biomed Res. 2012;3:49-51.

12. Khustagi, Surpaneni N. A thought for tramadol hydrochloride as labor analgesic. Anaes Essays Res. 2012;6:147-50.

13. Kaur Makkar J, Jain K, Bhatia N, Jain V, Mal Mithrawal S. Comparison of analgesic efficacy of paracetamol and tramadol for pain relief in active labor. J Clin Anesth. 2015;27:159-63.

14. Lallar M, Anam H, Nandal R, Singh SP, Katyal S. Intravenous paracetamol infusion versus intramuscular Tramadol as an intrapartum labor analgesic. J Obstet Gynaecol India. 2015;65:17-22.

Cite this article as: Raheja A, Agarwal K, Pachori $\mathrm{R}$, Gandhi G. Tramadol versus placebo for labor analgesia in low risk women: a randomized controlled trial. Int J Reprod Contracept Obstet Gynecol 2020;9:342-7. 